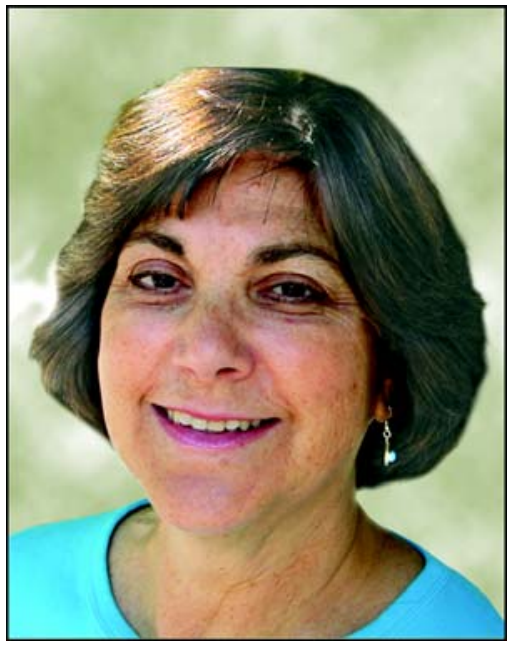

Marianne Farkas, ScD

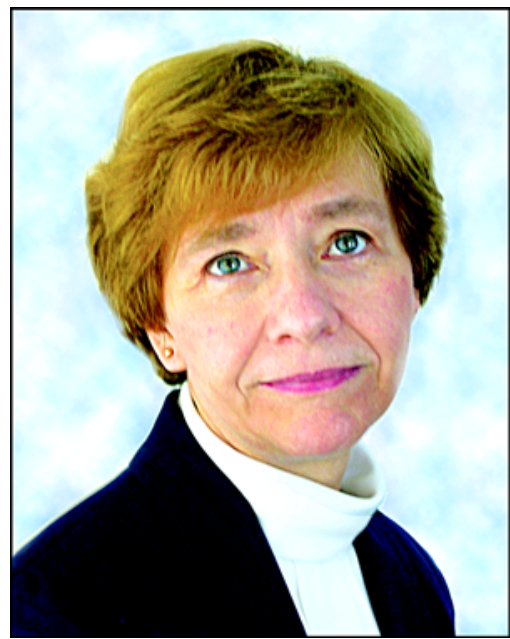

Mary A. Jansen, PhD

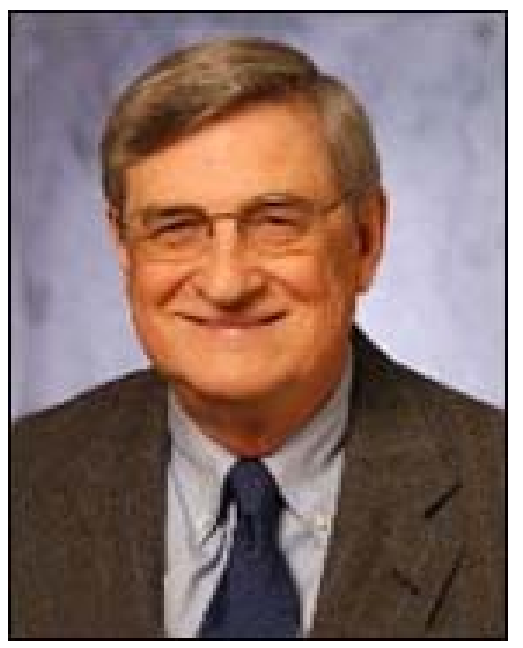

Walter E. Penk, PhD, ABPP

\section{Psychosocial rehabilitation: Approach of choice for those with serious mental illnesses}

We begin by thanking the Editor of the Journal of Rehabilitation Research and Development (JRRD) for commissioning a special issue on psychosocial rehabilitation (PSR) for persons with serious mental illnesses.

For many years, the conventional wisdom in the field of mental health has been that serious mental illnesses result in inevitable deterioration. Professional practice has therefore focused on managing psychopathology and its symptoms. A wider variety of outcomes has been identified as critical over the past 30 years, however, particularly for individuals with schizophrenia [1-4]. These outcomes include regaining functioning over the long term, developing friendships, and living satisfying lives [5-9]. Thirty years of empirical evidence, as well as first-person accounts [10-13], support the notion that recovery from serious mental illnesses is possible.

As a result, governments in several countries have convened expert panels to review the evidence and recommend policy about the kinds of services that are best for those with serious mental illnesses. In the United States, the three most widely recognized of these are the 1999 report of the Surgeon General on mental health [14], the recommendations of the President's New Freedom Commission on Mental Health [15], and the Institute of Medicine's report on mental health and substance abuse [16]. The single most potent recommendation is to introduce a vision of recovery into the mental health system, a vision based on the accumulated evidence of what is possible.

The result is that nothing less than recovery from serious mental illnesses has become the guiding force behind policies and practices in many U.S. Federal and state mental health systems, as well as those of other countries such as Canada and New Zealand [15,17-19].

\section{PSYCHOSOCIAL REHABILITATION IN CONTEXT OF RECOVERY}

The vision of recovery should be the unifying mission of all mental health services $[9,15,20]$. Each service should clearly identify the recovery outcomes for which it holds itself responsible. In this context, PSR or psychiatric rehabilitation services contribute to recovery by focusing on outcomes related to role functioning in the "real-world" community [20].

Rehabilitation of any kind (i.e., physical, psychiatric, social, etc.) is an ecological approach ("person-environment fit") that fits the framework of the consequences of disease and the goals of health proposed by the World

*U.S. Department of Veterans Affairs. Mental health strategic plan. Washington (DC): U.S. Department of Veterans Affairs; 2004. 
Health Organization (WHO) (i.e., classifying intervention effects in terms of their contribution to health, activity, and participation) [21]. PSR is concerned with return of functional capacity and participation in valued societal roles. The dictionary definition of rehabilitation is "the restoration of someone to a useful place in society" (http:// www.thefreedictionary.com/rehabilitation). Rehabilitation thus has two goals: facilitating success and satisfaction in the performance of personally preferred and valued roles and creating or promoting an increase in opportunities for participation in society. These goals are accomplished by ensuring that the person has the skills and supports necessary for success and satisfaction, a basic principle of PSR [20]. Techniques designed to promote role competencies, support for role success, and interventions to increase empowerment and societal opportunities and reduce discrimination are all within the pantheon of recognized rehabilitation techniques [22].

The PSR field is relatively young and still at the earliest stage of researching the interventions that constitute it. While well-executed randomized clinical trials (RCTs) are considered the "gold standard" for rigorous research, recent caveats have emerged about RCTs, especially in psychosocial intervention [23-24]. These caveats particularly apply when the goal is recovery, as opposed to more limited outcomes, such as preventing relapse or rehospitalization, for example. While weighing in regularly on the importance of evidence-based practices (EBPs) for those with serious mental illnesses, many prominent researchers are calling for a broader variety of rigorous research designs that are more consonant with the multidimensionality of recovery and the state of our current understanding [25-27]. In fact, the National Institute of Disability Rehabilitation Research (NIDRR) has funded several efforts to develop a research classification system that includes these non-RCT designs. ${ }^{*}$ Consequently, the field of disability studies, including PSR, is cur-

\footnotetext{
*Farkas M, Rogers ES. Innovative knowledge dissemination and utilization for disability and professional stakeholders, National Institute of Disability Rehabilitation Research, grant H133A050006. Continuation Report. Washington (DC); 2007.
}

rently built mostly on a hierarchy of evidence including quasi-experimental studies, open clinical trials, systematic observations, rigorous qualitative studies, and some true RCTs [26,28].

An important principle of today's mental health systems is that the individual should be engaged in the design, delivery, and evaluation of services. Research data suggest that outcomes are better for people who are meaningfully involved in the planning and delivery of their services [29]. Consumer involvement in designing and delivering mental health services (e.g., program planning, implementation, and evaluation) is seen as a critical component of a quality management system for any mental health service [30]. Given that recovery is predicated on an individual's full involvement and that the integration of services based on his or her specific contribution to the recovery mission is important for achieving the recovery goal, mental health systems are now focusing on the development of overall recovery plans. Department of Veterans Affairs (VA) mental health services, for instance, have begun to use the recovery terminology and are one of the first systems to have designated the development of recovery teams and recovery plans as an institutional initiative. ${ }^{\dagger}$ Recovery plans include goals and objectives that relate to individual services (e.g., treatment goals, rehabilitation goals, crisis intervention goals, etc.). Within an overall recovery plan, PSR plays in important role. A cornerstone of the field is the recognition that those who have serious mental illnesses must be full partners in the process and that, ultimately, they must be the arbiters of whatever services are designed to assist them.

PSR interventions are not limited to those with schizophrenia or other psychoses. Increasingly, they are recognized as effective for the symptoms of acute stress disorder and posttraumatic stress disorder (PTSD), especially when mental health practices are integrated into the experiences of supported

\footnotetext{
${ }^{\dagger}$ U.S. Department of Veterans Affairs. Recommendations of the recovery transformation work group to the executive committee of the Mental Health Steering Committee. Washington (DC): U.S. Department of Veterans Affairs; 2005.
} 
education and supported employment [31-32]. PSR interventions are likely to become even more important in the range of services offered by VA clinicians and others who work with Operation Enduring Freedom and Operation Iraqi Freedom combat veterans returning from war zones in Afghanistan and Iraq and undertaking the arduous challenges of transitioning from identities as combatants to identities as civilians.

As indicated, a commitment to the highest level of outcomes requires services that provide medication and other treatment interventions where needed, as well as psychosocial interventions designed to help individuals live productively in the community [33]. Considerable research evidence has now accumulated on the effectiveness of several interventions associated with PSR and the promise of others. The recommendations of the highly respected Schizophrenia Patient Outcomes Research Team (PORT) [34-35] have become important in guiding mental health treatment. The PORT recommendations support adopting a comprehensive PSR model, based on a range of clinical interventions from pharmacological to psychosocial. The abstract of the most recent update of the PORT study summarizes its essence [35, p. 196]:

Since publication of the original Schizophrenia Patient Outcomes Research Team (PORT) treatment recommendations in 1998, considerable scientific advances have occurred in our knowledge about how to help persons with schizophrenia. Today an even stronger body of research supports the scientific basis of treatment. This evidence, taken in its entirety, points to the value of treatment approaches combining medications with psychosocial treatments, including psychological interventions, family interventions, supported employment, assertive community treatment, and skills training... Currently available treatment technologies, when appropriately applied and accessible, should provide most patients with significant relief from psychotic symptoms and improved opportunities to lead more fulfilling lives in the community....
As a result, PSR is recognized as the approach of choice for helping those with serious mental illnesses achieve success and satisfaction in a particular societal role. The following is a brief review of PSR interventions and models.

\section{EVIDENCE-BASED PRACTICE AND PSYCHOSOCIAL REHABILITATION INTERVENTIONS}

Although no consensus exists about what constitutes empirical evidence for an evidence base, some authors state that a practice is evidencebased when two or more RCTs compare the practice favorably with an alternative, established intervention or to no intervention [36-37].

The evidence that supports provision of several well-known and widely accepted clinical interventions has now accumulated to the point that these interventions are known as EBPs. Furthermore, for some of them, comprehensive tool kits have been developed that summarize the evidence supporting the practice, provide detailed implementation guidelines designed to ensure fidelity to the practice as it was developed and researched, and recommend training so that providers are adequately prepared to provide the intervention. Information on the EBP tool kits is available on the Web site of the U.S. Substance Abuse and Mental Health Services Administration (SAMHSA) at http://www.samhsa.gov under the heading "Mental Health System Transformation, Evidence-Based Practices Implementation Resource Kits” [38].

Those interventions that are generally agreed to be EBPs are assertive community treatment (ACT), supported employment (SE), Integrated Dual Diagnosis Treatment, Family Psychoeducation (FPsy), Illness Management and Recovery, and Medication Algorithm. Of these, ACT, SE, and FPsy are the EBPs usually associated with PSR interventions, since they focus on activities and participation rather than on issues of health, according to the WHO classification system. A short review of the PSR EBPs and widely researched and accepted clinical interventions follows. 


\section{Assertive Community Treatment}

The most well-known and researched EBP is ACT. ${ }^{*}$ Originally developed and researched in the late 1970s in Madison, Wisconsin [39], ACT and its adaptations as PACT (Program for ACT) and FACT (Family Assisted ACT) [40] have become a critical case- management service for individuals with serious mental illnesses, particularly in areas where the mental health system is complex, services are fragmented, and people have difficulty getting the services and support they need to prevent relapse. ACT was developed to respond to issues such as the immediate decrease in the type and intensity of services available to people upon leaving the hospital and for situations in which programs are only available for a limited time, programs deny services because of the problems caused by the symptoms of mental illnesses, or services simply do not exist.

ACT teams typically are multidisciplinary and provide people with the support, treatment, and rehabilitation services they need to continue living in the community. The types of services provided and the length of time those services are provided depend on individual needs. Team members pool their experience and knowledge, working together to ensure people have the effective assistance they need. Staff respond to individuals in the community 24 hours a day, 7 days a week. As people improve, the team decreases their interactions with them, but team members are available to provide additional support when needed. A team of 10 to 12 members with a total caseload of 100 persons is ideal, although teams serving a large number of individuals with acute needs may find that smaller caseloads are necessary until individuals stabilize. The cost of this increased staff may be recouped through a decrease in the use of more expensive inpatient services.

\section{What Does Research Evidence Indicate?}

ACT has been shown in repeated studies to reduce time spent in the hospital, especially for

*Description adapted from http://www.samhsa.gov/, U.S. SAMHSA; 2002. A tool kit is available for ACT from the Web site. those who use such services the most [41]. The model has been tested all over the world and similar results have been found [42-45]. ACT's effect on other outcomes (e.g., employment, living arrangements, etc.) is less robust and may reflect the unfortunate, but typical, lack of sufficient rehabilitation specialists on the team [46].

Who Should Receive Assertive Community Treatment?

Typically, people who receive services from an ACT program have not benefited from traditional treatment approaches. Their impairments may include difficulties with basic everyday activities such as keeping safe, caring for their basic physical needs, or maintaining safe and adequate housing; unemployment; substance abuse; homelessness; and involvement in the criminal justice system.

\section{Supported Employment}

Perhaps the second most researched EBP is $\mathrm{SE}^{\dagger}$ and, in particular, the individual placement and support (IPS) model developed by Drake and associates [47-48]. Because work is critical to getting on with life beyond illness, it is a vital concern for those with serious mental illnesses, and SE is therefore a central component of PSR. Strong outcome data exist to support the efficacy of SE for persons with serious mental illnesses. SE is a "place and train" model that uses the principle of on-the-job training as its cornerstone. This means that individuals with mental health disorders learn how to find and keep regular real-world jobs in the community and are provided continuous support to help them succeed.

Programs that have implemented evidencebased SE find that fewer crises occur because people are focused on developing their lives in the community and managing their illness more independently. The comprehensive and coordinated planning that occurs with SE leads to fewer crises, less chaos, and more structure. The ongoing support of the employment specialist, whose caseload is generally no more

\footnotetext{
${ }^{\dagger}$ Description adapted from http://www.samhsa.gov/, U.S. SAMHSA; 2002. A tool kit is available for SE from the Web site.
} 
than 25 clients, provides the help often needed to sustain employment [49]. Additionally, research has also found that when SE is combined with other mental health services, i.e., in a highly integrated model of service delivery, employment rates for those with serious mental illness can be more than double that of those who receive SE without additional integrated services [50] and individuals achieve significantly higher earnings and remain employed for longer periods [51].

The essential principles of SE are-

- Focus on competitive employment.

- Rapid job searches.

- Jobs tailored to individuals.

- Unlimited follow-along supports.

- Integration of SE and mental health services.

- Zero exclusion criteria (i.e., no one is screened out because they are not thought to be ready).

SE works most effectively in a clinical environment where clinical teams meet to communicate at least weekly. Employment specialists, an integral part of that team, attend all team meetings and actively participate in the meetings.

\section{What Does Research Evidence Indicate?}

Outcomes for SE have been shown to be much better than for traditional approaches (30\%-50\% employment rates vs $0 \%-15 \%)$. These finding have been replicated in several countries [52-54], particularly in those regions with a strong secondary employment market. One of the most comprehensive reviews of the research was a Cochrane review completed in 2001. This review of 18 RCTs found that SE was superior to programs that offered prevocational training [55]. As a result, the model is now recommended as the employment intervention of choice for those with serious mental illnesses who want to work.

\section{Who Should Receive Supported Employment?}

$\mathrm{SE}$ is appropriate for all individuals with serious mental illnesses who indicate some desire to work.

\section{Family Psychoeducation}

FPsy $^{*}$ is another EBP that has substantial research evidence to support its use. As its name implies, FPsy is the process of providing education and coping skills for consumers and their families. FPsy is generally provided in multifamily groups but can also be offered in single-family formats. Multifamily formats have the added benefit of allowing for the development of social support systems. Consent of the individual with the illness is always required. Information about the person's illness is provided along with information for both consumer and family about recognizing the onset of symptoms, coping with behavioral changes, effects of medication, and communication skills. FPsy teams the individual and family as partners in providing the service, not as objects of a treatment modality.

FPsy programs have several essential elements, including-

- Development of the relationship.

- Educational workshops.

- Skills building for community reentry.

- Social and vocational skills development.

To be effective, FPsy programs need to be at least 9 months long, and the best effects are shown for programs that continue for much longer and whose primary focus is on the needs and desires of the individual.

\section{What Does Research Evidence Indicate?}

Considerable research has confirmed the effectiveness of FPsy. Studies undertaken in several different countries over the past two decades have shown remarkable success in reducing rates of relapse. On average, rates of rehospitalization have consistently reduced by an average of 50 percent, with the range between 40 and 70 percent. In addition, rates of employment are significantly higher among those who have participated in FPsy. Other findings include improved family member well-being,

\footnotetext{
*Description adapted from http://www.samhsa.gov/, U.S. SAMHSA; 2002. A tool kit is available for FPsy from the Web site.
} 
decreases in negative symptoms, and decreased costs of general medical care [56-57]. Several meta-analyses have confirmed these results, and as a result, the PORT project included FPsy in its treatment recommendations [34-35].

\section{Who Benefits from Family Psychoeducation?}

FPsy has been shown to benefit those with serious mental illnesses and is recommended for everyone with serious mental illness. In cases where family members are not available or the individual does not want to include a family member, psychoeducation should be provided to the individual within an illness management framework.

\section{Cognitive Remediation}

Helping consumers develop different perspectives through exposure to new information, cognitive remediation, is a technique that has been widely used in various cognitively oriented interventions for various issues. For example, exposure to new information about ways to manage one's own illness has been established as an EBP curriculum [58]. Reframing and forming new impressions can create a new version of habitual patterns such as are promoted in neurolinguistic programming, cognitive restructuring, and Adlerian techniques of turning a perceived negative into a positive [59]. Reframing techniques and motivational interviewing have been used in the Boston University rehabilitation approach to improve individuals' readiness for rehabilitation [60]. Each of these cognitive remediation approaches uses a similar technique-providing new information that allows the individual to categorize and label his or her experience in a new and empowering way.

\section{What Does Research Evidence Indicate?}

Cognitive remediation techniques have been widely used in mental health systems around the world and much research has supported their efficacy [61-64]. Cognitive restructuring has been used to help clients with PTSD, as well as those with alcohol abuse disorders and depression, identify distorted or self-defeating ideas related to a traumatic experience [65]. Cognitive remediation studies indicate that self-esteem, among other variables, increases when paper-and-pencil learning is used to help individuals diagnosed with schizophrenia take an organized, conscious approach to information processing [66]. Cognitive reframing has been used in psychotherapy with individuals in an SE program to shift perspectives about negative work experiences that might affect tenure in employment [6768], as well as in peer-support programs such as GROW, in which reframing was found to be associated with better social adjustment [69]. Cognitive enhancement therapies use "mentalizing" to help individuals understand mental states not only in themselves but also in others [70], which has been found to be exceptionally important for those recovering from a first episode of a serious mental illness [71]. Numerous studies demonstrate the effectiveness of cognitive remediation, some of which show enhanced effects when combined with other rehabilitation interventions such as SE.

\section{Who Should Receive Cognitive Remediation?}

Cognitive remediation techniques have been used with individuals with various mental illnesses, including individuals early in their mental illnesses, individuals with schizophrenia later in their course, individuals with PTSD, those with substance abuse disorders, and others.

\section{Skills Training}

Skills training is a well-known group of techniques intended to increase an individual's performance of a particular behavior or competency. Skills training can include behavior-shaping techniques derived from behavior modification, teaching techniques derived from the educational literature, or a combination of both. Behavior-shaping involves systematic practice and reinforcement of the desired behavior until a criterion is met. Teaching techniques involve didactic, modeling, and experiential practice with feedback until the skill is understood and in the control of the individual.

The concept of skills in PSR is much broader than daily living skills. PSR skills can encompass training in such essential tasks as negotiating a 
place to live, making friends in leisure time, analyzing implicit cues, and other everyday situations in which interaction with others is either necessary or beneficial. Most problematic to assess and teach are intrapersonal and interpersonal skills. Yet persons with psychiatric disabilities most often need help with these types of skills. Another skill area receiving increased attention is cognitive skills [72-74], implicated in a person's ability to learn more complex social skills. The basic hypothesis is that if attentional and perceptual skills can be learned first, then interpersonal skills learning would be more effective and efficient.

Like cognitive remediation techniques, rehabilitation skills training is not to reduce symptoms but rather to help those with serious mental illness improve their capacity to perform specific societal roles. Programs to improve standard skill sets or generic skills may or may not contribute to an individual's achievement of his or her goal. Skills training to improve those skills that a specific individual requires for the specific demands of a chosen vocation is essential for success in the community.

\section{What Does Research Evidence Indicate?}

In the 1980s and 1990s, researchers in social skills training, cognitive rehabilitation, and behavioral and educational skills training demonstrated that people with psychiatric disabilities can learn a number of different skills. Comprehensive reviews of the skills training research found conclusively that people with psychiatric disabilities can learn a wide variety of interpersonal and cognitive skills [75-76]. Arns and Linney found ratings of functional skills correlated positively with peoples' level of residential and vocational independence and concluded that skill level better predicts rehabilitation outcome than diagnostic variables [77]. Many studies have investigated the positive relationship between work-adjustment and interpersonal skills and vocational outcome measures. Every study that assessed work-adjustment skills found them to be related significantly to future work performance [78-80]. Liberman et al. found improvement in independent living skills at 2-year follow-up [81], and Smith et al. reported changes in initial community adjustment [82].

The broad category of clinical interventions known as skills training is not listed as an EBP, although like cognitive remediation, it is considered an integral part of all good mental health service delivery systems and a broad array of research evidence supports it [83-84].

\section{Who Benefits from Skills Training?}

Virtually everyone can benefit from skills training. Very few of us, whether or not we have a serious mental illness, can completely and adeptly handle every life situation that arises. Individuals with serious mental illnesses may need skills training in a wider array of life situations because of the cognitive deficits they have as a result of the illness or because their learning and socialization processes may have been delayed or impeded by episodes of illness. Skills training can help one learn how to fit more comfortably and effectively into normal, everyday society and therefore benefits anyone who wishes to handle such situations more efficiently.

\section{PROMISING PRACTICES}

In addition to the EBPs and clinical interventions described previously, various other interventions and program models are congruent with recovery values and have an empirical base but do not, as yet, have a series of RCTs associated with them and are thus not included in the list of EBPs. Examples are Boston University's Psychiatric Rehabilitation Approach, also known as the "Choose-Get-Keep" (CGK) approach, the Clubhouse Program Model, supported education, and peer support.

\section{Boston University's Psychiatric Rehabilitation Approach: Choose-Get-Keep}

More than two decades ago, the notion of the CGK model of PSR was conceptualized [85]. This CGK process was first described in the area of vocational rehabilitation for people with psychiatric disabilities and then extended over the years to the educational and housing environments [22]. Com- 
pared with other well-known program models in the mental health field, the PSR CGK process model is not setting-specific, like the Clubhouse Program Model [86], nor is it tied to a particular staffing pattern, as is the ACT program model [43], or integration of services, like the IPS model [87]. In contrast to a specific emphasis on discipline, setting, or service integration, the PSR CGK approach focuses on facilitating a specific practitioner and client process to guide the client to choose, get, and keep a rehabilitation goal. The CGK model defines the process both from the practitioner's point of reference and from that of the client. Various techniques have been synthesized to create a systematic process that involves clients in leading their own rehabilitation. For example, cognitive approaches helped orient people to each rehabilitation activity [88], client-centered psychotherapies contributed to the relationship-building process [89], and educational psychology contributed techniques related to skill teaching and coaching [90]. In essence, practitioners develop a personal connection with clients to facilitate or teach them how to-

- Assess their own readiness for change.

- Set their own goal in terms of the role they prefer (student, worker, tenant, etc.).

- Identify their own skill and resource strengths and deficits relative to this goal.

- Develop a plan.

- Use new skills or organization strategies to overcome the barriers to using skills they have, or link to existing resources or create new resources.

These activities are what practitioners do to facilitate rehabilitation [20,91]. Choosing, getting, and keeping are what individuals with serious mental illnesses do to achieve success and satisfaction in the societal roles they prefer. The critical ingredient of this approach is an emphasis on developing practitioner competencies in engaging, supporting, and teaching people how to drive and master their own rehabilitation process, regardless of their level of functioning. The process can be explained simply to individuals, their family members, and other professionals. Training manuals and program standards exist to support implementation of the approach
[92-98]. Training and consultation programs have helped disseminate the process in the United States, Canada, Europe, Australia, New Zealand, and some Asian countries. The approach has been used as the practitioner-consumer process in a variety of organizational program models (e.g., ACT, Clubhouse, inpatient facilities, supported housing, supported education, day programs, homeless programs, etc.) [90]. Preexperimental studies, quasi-experimental research, and two RCTs have been conducted on this approach in the domains of employment, housing, and education [99-101]. Positive outcomes have been identified in the areas of quality of life, housing status, work status, and other role functioning, as well as a decrease in service use [99,102].

\section{Clubhouse Program Model}

An innovation crucial to the early development of the PSR field was the creation of PSR centers, called Clubhouses. Fountain House in New York, New York, was and still is the most well-known of these centers and has led the way in developing and disseminating the Clubhouse Model [103]. The Clubhouse Model names individuals with mental illness as club members. As such, they have the right to choose whether and where to work, as well as which staff they work with; access to any records kept by the Clubhouse; and a lifetime right of reentry and community support services. Integral to the model are daily activities that allow club members to participate in all the work activities of the Clubhouse itself, including administration, outreach, hiring, training and evaluating staff, and researching the effectiveness of the Clubhouse. The Clubhouse operates on the concept of a "work-ordered" day in which members and staff work together to perform jobs essential to the functioning of the Clubhouse. Fountain House also originated the concept of transitional employment and broadened the concept to an early form of SE, the practice that was ultimately formulated into the EBP in use today. SE, including transitional employment, is a critical characteristic of a Clubhouse. More than 400 Clubhouse programs around the world are linked through the International Center for Clubhouse Development. Growing, but mostly uncontrolled, evidence exists of 
the effectiveness of the Clubhouse Model [104-106], particularly in employment outcomes of transitional employment programs.

\section{Supported Education}

Supported education has accumulated some research evidence and consequently is considered a promising practice [107-109]. Increasingly, practitioners recognize that individuals with serious mental illnesses have the same needs and desires for educational achievement and the same ability to achieve their goals with support from the mental health system [20]. As many young individuals benefit from the newer pharmacological treatments and are not hospitalized for long time periods, more are interested in resuming their educational goals quickly, but they often need extra assistance $[99,110]$. Consequently, this rehabilitation practice is increasingly recognized as critical to advance long-term career aspirations of individuals with serious mental illnesses and thus is important in a comprehensive service delivery system.

Supported education primarily provides opportunities, resources, and supports to people with serious mental illnesses so that they may gain admittance to and succeed in the pursuit of postsecondary education. Although supported education was developed primarily to help people return to postsecondary education, the principles and practices also apply to adolescents who are transitioning from high school to college and to adults who are completing the general equivalency diploma or participating in adult education. The process helps people who have a diagnosis of mental illness return to education so they can gain the knowledge and training necessary to achieve their recovery goals and/or become gainfully employed in the career of their choice [111].

The following are considered critical components in a supported education program:

- The mental health system promotes supported education.

- A supported education team or specialist is designated to work with individuals.
- A supported education program has no noneducational eligibility requirements for entrance into the program.

- A supported education specialist completes educational assessments with individuals.

- Communication and collaboration occur between all stakeholders.

- A supported education program offers confidenceand knowledge-building activities.

- A supported education program offers preparatory options.

- Preparatory classes are not required by the supported education program for school enrollment.

- The program offers support and assistance to acquire necessary resources for school attendance.

- The program provides enrollment and educational supports [112].

\section{Peer Support}

Peer support is currently the focus of intense research interest as a critical service for promoting recovery. Those with serious mental illness universally indicate that they believe peer support is one of the most helpful interventions they have experienced. Several studies have confirmed these perceptions [113-114]. Peer support groups are run by individuals with serious mental illness for others who have similar problems. Peers listen, share their own experiences, and offer support, hope, encouragement, and practical suggestions. Peer leaders can be trained to engage in active and supportive listening and to lead the groups themselves. Presently, a variety of peer support training programs are available. The best known include programs such as META Peer Employment Training Program (META Services, Inc, Phoenix, Arizona [gene@metaservices.com]), Intentional Peer Support (Shery Mead Consulting, Plainsfield, New Hampshire [shery@mentalhealthpeers.com]), and Georgia's model of Peer Specialist Training (http://www. gacps.org/ConsumerManual.html). Professional clinicians can also sit in on the groups but in no case would the clinician run the group. Peer support can also be offered individually by someone who has a serious mental illness and has recovered enough to 
help others. Training in basic communication and counseling skills is provided to ensure that the peer support worker is skilled enough to offer a helpful intervention. Many believe that peer support programs help normalize the experience of serious mental illness while traditional treatment tends to medicalize and stigmatize it.

\section{CONCLUSIONS}

Several of the EBPs and other accepted PSR interventions described here are the subject of this special issue of $J R R D$. The articles in this issue report both domestic and international research in PSR and showcase the worldwide convergence of evidence and practice advances for helping those with serious mental illness achieve optimal functional capability. In addition, some articles discuss issues related to dissemination of these practices. Others demonstrate the benefits of PSR, including the ability to overcome the helplessness associated with trauma by increasing competence and a sense of mastery in coping with the challenges of living a life shattered by trauma. PSR techniques address the social isolation and avoidance of social interactions that are the hallmark of many severe and persisting mental disorders and trauma.

Our hope and our goal are that the articles presented in this issue will increase and inspire research that validates efficacy and effectiveness of these and other PSR interventions. Moreover, we hope the studies presented herein will lead others to seek a deeper understanding of how psychosocial interventions produce the positive results that have enabled those with serious mental illnesses to resume normal, productive lives in the community. Finally, we hope that the articles will encourage those working in the field to not only raise their expectations of what those with serious mental illness can achieve, including the possibility of recovery, but also ensure that services like PSR that promote recovery outcomes are accessible to everyone.

\section{ACKNOWLEDGMENTS}

The views expressed in this article do not necessarily represent the views of the NIDRR or the Center for Mental Health Services (CMHS) but are solely the responsibility of the authors.

This material was based on work supported in part by NIDRR within the Department of Education, and CMHS, a division of SAMHSA, grant H133B040026.

\section{REFERENCES}

1. DeSisto MJ, Harding CM, McCormick RV, Ashikaga T, Brooks GW. The Maine and Vermont threedecade studies of serious mental illness. I. Matched comparison of cross-sectional outcome. Br J Psychiatry. 1995;167(3):331-38. [PMID: 7496641]

2. Harding CM, Brooks GW, Ashikaga T, Strauss JS, Breier A. The Vermont longitudinal study of persons with severe mental illness. I. Methodology, study sample, and overall status 32 years later. Am J Psychiatry. 1987;144(6):718-26. [PMID: 3591991]

3. Harding CM, Brooks GW, Ashikaga T, Strauss JS, Breier A. The Vermont longitudinal study of persons with severe mental illness. II. Long-term outcomes of subjects who retrospectively met DSM-III criteria for schizophrenia. Am J Psychiatry. 1987; 144(6):727-35. [PMID: 3591992]

4. Sartorius N, Gulbinat W, Harrison G, Laska E, Siegel C. Long-term follow-up of schizophrenia in 16 countries. A description of the International Study of Schizophrenia conducted by the World Health Organization. Soc Psychiatry Psychiatr Epidemiol. 1996;31(5):249-58. [PMID: 8909114]

5. Harding CM, Zahniser JH. Empirical correction of seven myths about schizophrenia with implications for treatment. Acta Psychiatr Scand Suppl. 1994; 384:140-46. [PMID: 7879636]

6. Harding CM, Strauss JS. How serious is schizophrenia? Comments on prognosis. Biol Psychiatry. 1984;19(12):1597-1600. [PMID: 6518210]

7. Liberman RP, Kopelowicz A, Ventura J, Gutkind D. Operational criteria and factors related to recovery from schizophrenia. Int Rev Psychiatry. 2002;14(4): 256-72. 
8. Ridgway PA. Re-storying psychiatric disability: Learning from first person narrative accounts of recovery. Psychiatr Rehabil J. 2000;24(4):335-43.

9. Farkas M, Gagne C, Anthony WA, Chamberlin J. Implementing recovery oriented evidence based programs: Identifying the critical dimensions. Community Ment Health J. 2005;41(2):141-58.

[PMID: 15974495]

10. Deegan P. Recovery as a journey of the heart. Psychiatr Rehabil J. 1996;19(3):91-97.

11. Fisher D, Ahern L. People can recover from mental illness. Nat Empowerment Cent Newsl. 1999; Spring: 8-9.

12. Leete E. How I perceive and manage my illness. Schizophr Bull. 1989;15(2):197-200.

[PMID: 2749182]

13. Mead S, Copeland ME. What recovery means to us: Consumers' perspectives. Community Ment Health J. 2000;36(3):315-28. [PMID: 10933247]

14. Satcher D. Mental health: A report of the surgeon general. Rockville (MD): U.S. Department of Health and Human Services; 1999.

15. Hogan MF. New Freedom Commission Report: The President's New Freedom Commission: Recommendations to transform mental health care in America. Psychiatr Serv. 2003;54:1467-74.

16. Institute of Medicine. Improving the quality of health care for mental and substance-use conditions. Washington (DC): National Academies Press; 2006.

17. Bellack AS. Scientific and consumer models of recovery in schizophrenia: Concordance, contrasts, and implications. Schizophr Bull. 2006;32(3):432-42. [PMID: 16461575]

18. Beale V, Lambric T. The recovery concept: Implementation in the mental health system: A report. Columbus (OH): Ohio Department of Mental Health; 1995.

19. Gawith L, Abrams P. Long journey to recovery for Kiwi consumers: Recent developments in mental health policy and practice in New Zealand. Aust Psychol. 2006;41(2):140-48.

20. Anthony WA. Psychiatric rehabilitation. 2nd ed. Boston (MA): Center for Psychiatric Rehabilitation, Sargent College of Health and Rehabilitation Sciences, Boston University; 2002.

21. De Kleijn-De Vrankrijker MW. The long way from the International Classification of Impairments, Disabilities and Handicaps (ICIDH) to the International Classification of Functioning, Disability and
Health (ICF). Disabil Rehabil. 2003;25(11-12): 561-64. [PMID: 12959328]

22. Farkas MD, Anthony WA. Psychiatric rehabilitation programs: Putting theory into practice. Baltimore (MD): Johns Hopkins University Press; 1989.

23. Ablon JS, Marci C. Psychotherapy process: The missing link: Comment on Westen, Novotny, and Thompson-Brenner. Psychol Bull. 2004;130(4): 664-68. [PMID: 15250816]

24. Westen D, Novotny CM, Thompson-Brenner H. The empirical status of empirically supported psychotherapies: Assumptions, findings and reporting in controlled clinical trials. Psychol Bull. 2004; 130(4):631-63. [PMID: 15250817]

25. Anthony WA. Taking issue: Studying evidence based processes, not practices. Psychiatr Serv. 2003; 54(1):7.

26. Anthony W, Rogers ES, Farkas M. Research on evidence-based practices: Future directions in an era of recovery. Community Ment Health J. 2003; 39(2):101-14. [PMID: 12723845]

27. Essock SM, Goldman HH, Van Tosh L, Anthony WA, Appell CR, Bond GR, Dixon LB, Dunakin LK, Ganju V, Gorman PG, Ralph RO, Rapp CA, Teague GB, Drake RE. Evidence-based practices: Setting the context and responding to concerns. Psychiatr Clin North Am. 2003;26(4):919-38. [PMID: 14711128$]$

28. Drake RE, Rosenberg SD, Teague GB, Bartels SJ, Torrey WC. Fundamental principles of evidencebased medicine applied to mental health care. Psychiatr Clin North Am. 2003;26(4):811-20.

\section{[PMID: 14711121]}

29. Majumder RK, Walls RT, Fullmer SL. Rehabilitation client involvement in employment decisions. Rehabil Couns Bull. 1998;42(2):162-73.

30. Blackwell B, Eilers K, Robinson D Jr. The consumer's role in assessing quality. In: Stricker G, Troy WG, editors. Handbook of quality management in behavioral health: Issues in the practice of psychology. Dordrecht (the Netherlands): Kluwer Academic Publishers; 2000. p. 375-86.

31. Penk WE, Flannery RB. Psychosocial rehabilitation. In: Foa EB, Keane TM, editors. Effective treatments for PTSD: Practice guidelines from the International Society for Traumatic Stress Studies. New York (NY): Guilford Press; 2000. p. 224-46.

32. Glynn S, Drebing C, Penk WE. Psychosocial rehabilitation. In: Foa EB, Keane TM, editors. Effective treatments for PTSD: Practice guidelines from the 
International Society for Traumatic Stress Studies. New York (NY): Guilford Press. In press 2000.

33. Schwartz MS, Perkins DO, Stroup TS, Davis SM, Capuano G, Rosenheck RA, Reimherr F, McGee MF, Keefe RS, McEvoy JP, Hsiao JK, Lieberman JA; CATIE Investigators. The effects of antipsychotic medications on psychosocial functioning in patients with chronic schizophrenia: Findings from the NIMH CATIE study. Am J Psychiatry. 2007; 164(3):428-36. [PMID: 17329467]

34. Lehman AF, Steinwachs DM. Translating research into practice: The Schizophrenia Patient Outcomes Research Team (PORT) treatment recommendations. Schizophr Bull. 1998;24(1):1-10.

[PMID: 9502542]

35. Lehman AF, Kreyenbuhl J, Buchanan RW, Dickerson FB, Dixon LB, Goldberg R, Green-Paden LD, Tenhula WN, Boerescu D, Tek C, Sandson N, Steinwachs DM. The Schizophrenia Patient Outcomes Research Team (PORT): Updated treatment recommendations 2003. Schizophr Bull. 2004;30(2): 193-217. [PMID: 15279040]

36. Chambless DL, Ollendick TH. Empirically supported psychological interventions: Controversies and evidence. Annu Rev Psychol. 2001;52:685-716. [PMID: 11148322]

37. Phillips SD, Burns BJ, Edgar ER, Mueser KT, Linkins KW, Rosenheck RA, Drake RE, McDonel Herr EC. Moving assertive community treatment into standard practice. Psychiatr Serv. 2001;52(6): 771-79. [PMID: 11376224]

38. U.S. Substance Abuse and Mental Health Services Administration. Mental health system transformation, evidence based practices implementation resource kits. Rockville (MD): U.S. Substance Abuse and Mental Health Services Administration; 2002.

39. Stein LL, Test MA. Alternative to mental hospital treatment. I. Conceptual model, treatment program, and clinical evaluation. Arch Gen Psychiatry. 1980; 37(4):392-97. [PMID: 7362425]

40. McFarlane WR, Dushay RA, Deakins SM, Stastny P, Lukens EP, Toran J, Link B. Employment outcomes in family-aided assertive community treatment. Am J Orthopsychiatry. 2000;70(2):203-14. [PMID: 10826032]

41. Mueser KT, Bond GR, Drake RE, Resnick SG. Models of community care for severe mental illness. A review of research on case management. Schizophr Bull. 1998;24(1):37-74.

[PMID: 9502546]
42. Bond GR, Drake RF, Mueser KT, Latimer EA. Assertive community treatment for people with severe mental illness: Critical ingredients and impact on patients. Dis Manage Health Outcomes. 2001;9(3): 141-59.

43. Burns BJ, Santos AB. Assertive community treatment: An update of randomized trials. Psychiatr Serv. 1995;46(7):669-75. [PMID: 7552556]

44. Latimer EA. Economic impacts of assertive community treatment: A review of the literature. Can J Psychiatry. 1999;44(5):443-54. [PMID: 10389605]

45. Solomon P, Draine J. One-year outcomes of a randomized trial of case management with seriously mentally ill clients leaving jail. Eval Rev. 1995; 19(3): 256-74.

46. Ahrens C, Frey J, Burke S. An individual job engagement approach for people with severe mental illness. J Rehabil. 1999;65(4):17-24.

47. Drake RE, Becker DR, Clark RE, Mueser KT. Research on the individual placement and support model of supported employment. Psychiatr Q. 1999; 70(4):289-301. [PMID: 10587985]

48. Drake RE. A brief history of the individual placement and support model. Psychiatr Rehabil J. 1998; 22(1):3-7.

49. Bond GR, Becker DR, Drake RE, Rapp CA, Meisler N, Lehman AF, Bell MD, Blyler CR. Implementing supported employment as an evidence-based practice. Psychiatr Serv. 2001;52(3): 313-22. [PMID: 11239097]

50. Cook JA, Lehman AF, Drake RE, McFarlane WR, Gold PB, Leff HS, Blyler CR, Toprac MG, Razzano LA, Burke-Miller JK, Blankertz LE, Shafer M, Pickett-Schenk SA, Grey DD. Integration of psychiatric and vocational services: A multisite randomized, controlled trial of supported employment. Am J Psychiatry. 2005;162(10):1948-56. [PMID: 16199843]

51. Cook JA, Leff HS, Blyler CR, Gold PB, Goldberg RW, Mueser KT, Toprac MG, McFarlane WR, Shafer MS, Blankertz LE, Dudek K, Razzano LA, Grey DD, Burke-Miller JK. Results of a multisite randomized trial of supported employment interventions for individuals with severe mental illness. Arch Gen Psychiatry. 2005;62(5):505-12. [PMID: 15867103]

52. Bond GR, Drake RE, Mueser KT, Becker DR. An update on supported employment for people with severe mental illness. Psychiatr Serv. 1997;48(3): 335-46. [PMID: 9057235] 
53. Latimer EA, Lecomte T, Becker DR, Drake RE, Duclos I, Piat M, Lahaie N, St-Pierre MS, Therrien C, Xie H. Generalisability of the individual placement and support model of supported employment: Results of a Canadian randomised controlled trial. Br J Psychiatry. 2006;189:65-73. [PMID: 16816308]

54. Oldman J, Thomson L, Calsaferri K, Luke A, Bond GR. A case report of the conversion of sheltered employment to evidence-based supported employment in Canada. Psychiatr Serv. 2005;56(11): 1436-40. [PMID: 16282264]

55. Crowther R, Marshall M, Bond G, Huxley P. Vocational rehabilitation for people with severe mental illness. Cochrane Database Syst Rev. 2001;(2): CD003080. [PMID: 11406069]

56. Campbell AS. How was it for you? Families' experiences of receiving behavioural family therapy. J Psychiatr Ment Health Nurs. 2004;11(3): 261-67. [PMID: 15149372]

57. Dixon L, McFarlane WR, Lefley H, Lucksted A, Cohen M, Falloon I, Mueser K, Miklowitz D, Solomon P, Sondheimer D. Evidence-based practices for services to families of people with psychiatric disabilities. Psychiatr Serv. 2001;52(7):903-10. [PMID: 11433107]

58. Mueser KT, Corrigan PW, Hilton DW, Tanzman B, Schaub A, Gingerich S, Essock SM, Tarrier N, Morey B, Voge-Scibilia S, Herz MI. Illness management and recovery: A review of the research. Psychiatr Serv. 2002;53(10):1272-84.

[PMID: 12364675]

59. Eckstein D. 'Reframing' as an innovative educational technique: Turning a perceived inability into an asset. Korean J Thinking Probl Solv. 2004;14(1): 37-48.

60. Farkas MD, Sullivan-Soydan A, Gagne C. Introduction to rehabilitation readiness. Boston (MA): Boston University, Center for Psychiatric Rehabilitation; 2000.

61. Cather C, Penn DL, Otto MW, Yovel I, Mueser KT, Goff DC. A pilot study of functional Cognitive Behavioral Therapy (fCBT) for schizophrenia. Schizophr Res. 2005;74(2-3):201-9.

[PMID: 15722000]

62. Gould RA, Mueser KT, Bolton E, Mays V, Goff D. Cognitive therapy for psychosis in schizophrenia: An effect size analysis. Schizophr Res. 2001;48(2-3): 335-42. [PMID: 11295385]

63. Haddock G, Barrowclough C, Tarrier N, Moring J, O’Brien R, Schofield N, Quinn J, Palmer S, Davies
L, Lowens I, McGovern J, Lewis S. Cognitivebehavioural therapy and motivational intervention for schizophrenia and substance misuse. 18-month outcomes of a randomised controlled trial. Br J Psychiatry. 2003;183:418-26. [PMID: 14594917]

64. Kavanagh DJ, Mueser KT. The future of cognitive and behavioural therapies in the prevention and early management of psychosis: Opportunities and risks. Behav Ther. 2001;32:693-724.

65. Rosenberg SD, Mueser KT, Friedman MJ, Gorman PG, Drake RE, Vidaver RM, Torrey WC, Jankowski MK. Developing effective treatments for posttraumatic disorders among people with severe mental illness. Psychiatr Serv. 2001;52(11):1453-61. [PMID: 11684740]

66. Spaulding WD, Reed D, Sullivan M, Richardson C, Weiler M. Effects of cognitive treatment in psychiatric rehabilitation. Schizophr Bull. 1999;25(4):657-76. [PMID: 10667738]

67. Lysaker PH, France CM. Psychotherapy as an element in supported employment for persons with severe and persistent mental illness. Psychiatry. 1999;62(3):209-21. [PMID: 10612113]

68. McGurk SR, Mueser KT, Feldman K, Wolfe R, Pascaris A. Cognitive training for supported employment: 2-3 year outcomes of a randomized controlled trial. Am J Psychiatry. 2007;164(3):437-41. [PMID: 17329468]

69. Roberts LJ, Salem D, Rappaport J, Toro PA, Luke DA, Seidman E. Giving and receiving help: Interpersonal transactions in mutual-help meetings and psychosocial adjustment of members. Am J Community Psychol. 1999;27(6):841-68. [PMID: 10723537]

70. Allen JG. Mentalizing. Bull Menninger Clin. 2003; 67(2):91-112. [PMID: 14604096]

71. Miller R, Mason SE. Cognitive enhancement therapy: A therapeutic treatment strategy for first-episode schizophrenia patients. Bull Menninger Clin. 2004; 68(3):213-30. [PMID: 15342329]

72. Green MF. What are the functional consequences of neurocognitive deficits in schizophrenia? Am J Psychiatry. 1996;153(3):321-30. [PMID: 8610818]

73. Green MF, Kern RS, Braff DL, Minz J. Neurocognitive deficits and functional outcomes in schizophrenia: Are we measuring the "right stuff"? Schizophr Bull. 2000;26(1):119-36. [PMID: 10755673]

74. Spaulding WD, Fleming SK, Reed D, Sullivan M, Storzbach D, Lam M. Cognitive functioning in 
schizophrenia: Implications for psychiatric rehabilitation. Schizophr Bull. 1999;25(2):275-89. [PMID: 10416731]

75. Benton MK, Schroeder HE. Social skills training with schizophrenics: A meta-analytic evaluation. J Consult Clin Psychol. 1990;58(6):741-47. [PMID: 2149858]

76. Dilk MN, Bond GR. Meta-analytic evaluation of skills training research for individuals with severe mental illness. J Couns Clin Psychol. 1996;64(6): 1337-46. [PMID: 8991320]

77. Arns PG, Linney JA. Relating functional skills of severely mentally ill clients to subjective and societal benefits. Psychiatr Serv. 1995;46(3):260-65. [PMID: 7796214]

78. Anthony WA, Rogers ES, Cohen M, Davies RR. Relationships between psychiatric symptomatology, work skills, and future vocational performance. Psychiatr Serv. 1995;46(4):353-58. [PMID: 7788456]

79. Bond GR, Friedmeyer MH. Predictive validity of situational assessment at a psychiatric rehabilitation center. Psychosoc Rehabil J. 1987;11:61-77.

80. Bryson G, Bell MM, Greig T, Kaplan E. The Work Behavior Inventory: Prediction of future work success of people with schizophrenia. Psychiatr Rehabil J. 1999;23(2):113-19.

81. Liberman RP, Wallace CJ, Blackwell G, Kopelowicz A, Vaccaro JV, Mintz J. Skills training versus psychosocial occupational therapy for persons with persistent schizophrenia. Am J Psychiatry. 1998; 155(8):1087-91. [PMID: 9699698]

82. Smith TE, Hull JW, MacKain SJ, Wallace CJ, Rattenni LA, Goodman M, Anthony DT, Kentros MK. Training hospitalized patients with schizophrenia in community reintegration skills. Psychiatr Serv. 1996; 47(10):1099-1103. [PMID: 8890338$]$

83. Bustillo J, Lauriello J, Horan W, Keith S. The psychosocial treatment of schizophrenia: An update. Am J Psychiatry. 2001;158(2):163-75. [PMID: 11156795]

84. Penn DL, Mueser KT. Research update on the psychosocial treatment of schizophrenia. Am J Psychiatry. 1996;153(5):607-17. [PMID: 8615405]

85. Anthony WA, Howell J, Danley KS. Vocational rehabilitation of the psychiatrically disabled. In: Mirabi M, editor. The chronically mentally ill: Research and services. Jamaica (NY): Spectrum Publications; 1984. p. 215-37.

86. Macias C, Jackson R, Schroeder C, Wang Q. What is a clubhouse? Report on the ICCD 1996 survey of
USA clubhouses. Community Ment Health J. 1999; 35(2):181-90. [PMID: 10412626]

87. Becker DR, Drake RE. A working life: The Individual Placement and Support (IPS) program. Concord (NH): Dartmouth Psychiatric Research Center; 1993.

88. Brenner HD, Hodel B, Roder V, Corrigan P. Treatment of cognitive dysfunctions and behavioral deficits in schizophrenia. Schizophr Bull. 1992;18(1): 21-26. [PMID: 1553495]

89. Carkhuff RR, Berenson BG. Teaching as treatment: An introduction to counseling and psychotherapy. Amherst (MA): Human Resource Development Press; 1976.

90. Carkhuff RR, Anthony WA. The skills of helping: An introduction to counseling skills. Amherst (MA): Human Resource Development Press; 1979.

91. Farkas MD, Cohen MR, Nemec PB. Psychiatric rehabilitation programs: Putting concepts into practice? Community Ment Health J. 1988;24(1):7-21. [PMID: 3370939]

92. Cohen MR, Forbess R, Farkas M. Rehabilitation readiness training technology: Developing readiness for rehabilitation (Trainer package). Boston (MA): Boston University, Center for Psychiatric Rehabilitation; 2000.

93. Cohen MR, Danley KS, Nemec PB. Psychiatric rehabilitation training technology: Direct skills teaching (Trainer package). Boston (MA): Boston University, Center for Psychiatric Rehabilitation; 1985.

94. Cohen MR, Farkas MD, Cohen BF. Psychiatric rehabilitation training technology: Functional assessment (Trainer package). Boston (MA): Boston University, Center for Psychiatric Rehabilitation; 1986.

95. Cohen MR, Farkas MD, Cohen BF, Unger KV. Psychiatric rehabilitation training technology: Setting an overall rehabilitation goal (Trainer package). Boston (MA): Boston University, Center for Psychiatric Rehabilitation; 1991.

96. Cohen MR, Nemec P, Farkas M. Connecting skills for rehabilitation readiness. Boston (MA): Boston University, Center for Psychiatric Rehabilitation; 2000.

97. Cohen MR, Nemec PB, Farkas MD, Forbess R. Psychiatric rehabilitation training technology: Case management (Trainer package). Boston (MA): Boston University, Center for Psychiatric Rehabilitation; 1988.

98. Farkas MD, Cohen MR, McNamara S, Nemec PB, Cohen BF. Psychiatric rehabilitation training technology: Rehabilitation readiness (Trainer package). 
Boston (MA): Boston University, Center for Psychiatric Rehabilitation; 2000.

99. Hutchinson D, Anthony W, Massaro J, Rogers ES. Evaluation of a combined supported computer education and employment training for persons with psychiatric disabilities. Psychiatr Rehabil J. 2007; 30(3):189-97. [PMID: 17269269]

100. Shern DL, Tsemberis S, Anthony W, Lovell AM, Richmond L, Felton CJ, Winarski J, Cohen M. Serving street-dwelling individuals with psychiatric disabilities: Outcomes of a psychiatric rehabilitation clinical trial. Am J Public Health. 2000;90(12): 1873-78. [PMID: 11111259]

101. Rogers ES, Anthony WA, Toole J, Brown MA. Vocational outcomes following psychosocial rehabilitation: A longitudinal study of three programs. J Vocat Rehabil. 1991;1(3):21-29.

102. Rogers E, Anthony W, Farkas M. The Choose-GetKeep approach to psychiatric rehabilitation: A synopsis of recent studies. Rehabil Psychol. 2006;51(3): 247-56.

103. Propst RN. Stages in realizing the international diffusion of a single way of working: The clubhouse model. New Dir Ment Health Serv. 1997;(74):53-66. [PMID: 9262096]

104. Bilby R. A response to the criticism of transitional employment. Psychosoc Rehabil J. 1992;16(2):69-82.

105. Noble JH. The benefits and costs of supported employment for people with mental illness and with traumatic brain injury in New York State. Buffalo (NY): Research Foundation of the State University of New York; 1991.

106. McKay C, Johnsen M, Stein R. Employment outcomes in Massachusetts Clubhouses. Psychiatr Rehabil J. 2005;29(1):25-33. [PMID: 16075694]

107. Isenwater W, Lanham W, Thornhill H. The College Link Program: Evaluation of a supported education initiative in Great Britain. Psychosoc Rehabil J. 2002; 26(1):43-50. [PMID: 12171282]

108. Mowbray CT, Collins M, Bybee D. Supported education for individuals with psychiatric disabilities:
Long-term outcomes from an experimental study. Soc Work Res. 1999;23(2):89-102.

109. Unger KV, Pardee R, Shafer MS. Outcomes of postsecondary supported education programs for people with psychiatric disabilities. J Vocat Rehabil. 2000;14(3):195-99.

110. Unger KV, Anthony WA, Sciarappa K, Rogers ES. A supported education program for young adults with long-term mental illness. Hosp Community Psychiatry. 1991;42(8):838-42. [PMID: 1894260]

111. Mowbray CT. Supported education and psychiatric rehabilitation: Models and methods. Columbia (MD): International Association of Psychosocial Rehabilitation Services; 2002.

112. Ratzlaff S, McDiarmid D, Marty D, Rapp C. The Kansas Consumer as Provider program: Measuring the effects of a supported education initiative. Psychiatr Rehabil J. 2006;29(3):174-82. [PMID: 16450928]

113. Davidson L, Chinman M, Kloos B, Weingarten R, Stayner D, Tebes JK. Peer support among individuals with severe mental illness: The evidence. Clin Psychol. 1999;6(2):165-87.

114. Nelson G, Ochocka J, Janzen R, Trainor J. A longitudinal study of mental health consumer/survivor initiatives: Part 1-Literature review and overview of the study. J Community Psychol. 2006;34(3):247-60.

\section{Marianne Farkas, ScD; ${ }^{1 *}$ Mary A. Jansen, PhD $;^{2}$ Walter E. Penk, PhD, ABPP ${ }^{3-4}$}

${ }^{1}$ Center for Psychiatric Rehabilitation, Sargent College of Health and Rehabilitation Sciences, Boston University, Boston, MA; ${ }^{2}$ British Columbia Mental Health and Addiction Services, Provincial Health Services Authority, Vancouver, Canada; ${ }^{3}$ Texas A\&M Health Science Center College of Medicine, College Station, TX; ${ }^{4}$ Central Texas Department of Veterans Affairs Health Care Center, Temple, TX

*Email: mfarkas@bu.edu

DOI: 10.1682/JRRD.2007.09.0143 